Research Article

\title{
Dynamic Compression Properties of the Resistance Spot Welding of High Strength Steels under Varying Temperature Conditions
}

\author{
Chunlei Fan (D), ${ }^{1}$ Huanran Wang, ${ }^{2}$ and Dongfang $\mathrm{Ma}^{3}$ \\ ${ }^{1}$ Architectural Engineering Institute, Zhejiang Industry Polytechnic College, Shaoxing 312000, China \\ ${ }^{2}$ Key Laboratory of Impact and Safety Engineering, Ministry of Education, Ningbo University, Ningbo 315211, China \\ ${ }^{3}$ College of Science \& Technology, Ningbo University, Ningbo 315300, China
}

Correspondence should be addressed to Chunlei Fan; fan123submit@163.com

Received 26 March 2021; Revised 21 June 2021; Accepted 18 August 2021; Published 26 August 2021

Academic Editor: Claudio Pettinari

Copyright (C) 2021 Chunlei Fan et al. This is an open access article distributed under the Creative Commons Attribution License, which permits unrestricted use, distribution, and reproduction in any medium, provided the original work is properly cited.

In this paper, we have studied the dynamic compression performance of the RSW of QP980 steel and TRIP800 steel by using a split Hopkinson pressure bar (SHPB), and we have also examined the fracture mode of the two research objects. It is found that the spot welding zone is primarily composed of the martensite structure, and there is a sparse defect of crystal structure adjacent to the center of nugget. In addition, there are evident gaps between the plates on both sides of the spot welding zone. Through the measurement of the microhardness of the two grade steel, it is found that the average hardness of the RSW of QP980 steel is higher than that of TRIP800 steel. There is a softening region in the interface of the heat affected zone and the substrate zone. The dynamic compression experiments are carried out on the RSW of QP980 steel and TRIP800 steel under $200^{\circ} \mathrm{C}$ and $300^{\circ} \mathrm{C}$ conditions, and it is found that the strain rate would increase with the rising temperature, but the compressive strength would experience declines. Furthermore, the sparse defects of crystal structure adjacent to the center of nugget would lead to stress rebound when the specimen is compressed. Moreover, through the observation of the fracture surface of the recovered specimens, it is found that the fracture of the nugget is brittle, whereas the fracture mode of the sample is more complicated. In addition, the fracture surface features a number of "river pattern" cleavage facets, and there are very few dimples of ductile tearing. This study is expected to have huge implications to the safety of vehicle body under high-speed impact.

\section{Introduction}

Over the recent years, there has been constantly increasing use of high-strength steel plates in the automobile manufacturing industry. The QP980 steel and the TRIP800 steel manufactured by the Bao Steel Group have shown their advantages in terms of ultrahigh strength and ductility [1]. The QP980 steel is manufactured based on a novel process of quenching and distribution [2], whereas the TRIP800 steel features a TRIP effect. Some scholars have conducted studies on the deformation and fracture of QP980 steel [3-5]. Hu [6] determined the critical resolved shear stresses and hardening parameters of the constituent phases in QP980. Wang [7] provided the effects of strain rate and temperature on the dynamic tensile fracture strain of QP980 steel, whereas other scholars have studied the mechanical properties of TRIP800 steel [8-11]. Kussa [12] studied the austenite transformation kinetics and tensile properties of constructional $0.2 \mathrm{wt} \% \mathrm{C}$ Si2Mn2CrMoVNb TRIP-assisted steel. Fu [13] studied a low-alloyed C-Mn-Al-Si cold-rolled TRIP steel was tensile tested at room temperature and low temperature. In general, the sheet steel on the car body is connected by resistance spot welding. There are roughly 4,000 spot welds in a car, whose strength and stability under load are critical, as the car will bear all sorts of loads during manufacturing and use [14-16]. Noh [17] analyzed the failure of welded structures considering dissimilar combinations of advanced high-strength steels (AHSS) and a conventional mild steel. Soomro [18] carried out in situ postweld heat treatment by employing a double pulse welding scheme with the aim of improving the 
mechanical performance of DP590 steel resistance spot weld joint. Over the past few years, numerous scholars have conducted studies on solder joints. Sezgin [19] examined the electron beam welding (EBW) method of TRIP 800 steel and DP 1000 steel and found through observation that the TRIP 800 joining absorbed more energy than the DP 1000 joining at impact notch experiment for each temperature. Emre [20] studied the impact imposed by the welding current and welding time on nugget shape, while conducting the tensile shear experiment on welding specimens in the meantime. $\mathrm{Wu}$ [21] studied the fatigue properties of TRIP steel subsequent to resistance spot welding. The research findings indicate that the fatigue strength of the solder joint is only $8.9 \%$ of the original trip 800 steel. Through the observation with the scanning electron microscope (SEM), it is verified that the fatigue crack between HAZ and matrix is the cleavage fracture. Zsara [22] studied the resistance spot welding performance of AHSS steel TRIP800 (transformation induced plasticity) and HSLA steel. Analysis is conducted on the impact imposed by the welding time parameters on tensile and shear properties. Moreover, the study is conducted on the optimal parameters of tensile shear strength and the separation mode encountered. The maximum tensile shear load can be obtained with the use of 15 cycles. Most of them focus on the shear failure and fatigue properties of solder joints, but few center around their dynamic compression properties.

In this study, we have observed the microstructure of the RSW of QP980 steel and TRIP800 steel, and we have studied the metallographic composition and distribution of the two research objects. Moreover, we have conducted experiments on the Vickers hardness of the spot welding zone of both types of steel, studied the distribution of their hardness, and compared the measurement results of their Vickers hardness. We have conducted multiple dynamic compression experiments on the cylindrical specimens of the RSW of QP980 steel and TRIP800 steel at room temperature and under heating conditions, thereby obtaining the stress-strain curves to study the impact imposed by the metallurgical structure and temperature of the spot welding zone on dynamic compression properties. By using the scanning electron microscope (SEM), we have observed the fracture surface of the specimens so as to analyze the fracture patterns. When a car body suffers high-speed impact, strength and stability of the RSW joints will influence the security of the car body. Failure mechanism under impact loading is extremely vital in the safe design of the car body. Our research is expected to provide a certain basis and reference for the strength and safety design of RSW joint in automobile manufacturing.

\section{Methods}

The base materials used in the experiment include QP980 steel and TRIP800 steel, whose thickness amounts to $1.2 \mathrm{~mm}$ and $1.4 \mathrm{~mm}$, respectively. Through the overlap welding of the two types of steel, the overlap structure for RSW is obtained with one central spot weld, whose diameter amounts to $5 \mathrm{~mm}$, as shown in Figure 1. The spot welding

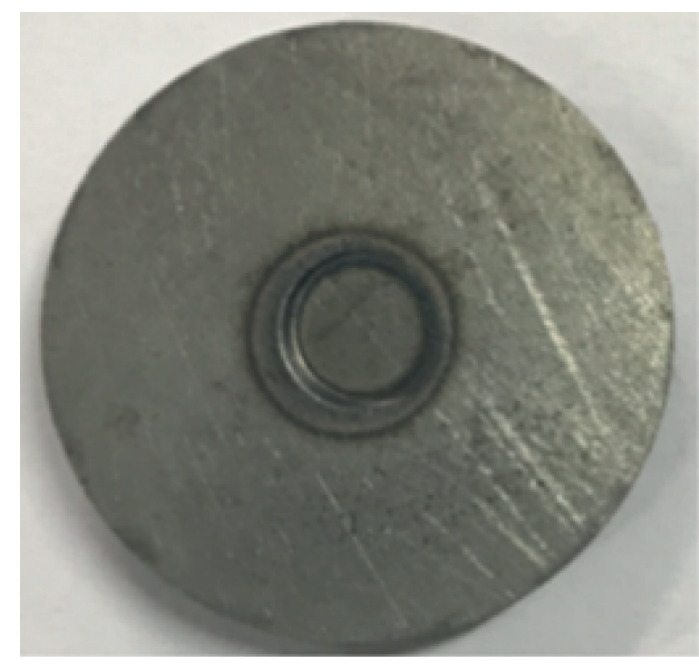

FIgURE 1: The overlap structure of RSW.

electrode is composite copper electrode, whereas the welding parameters are shown in Table 1. Subsequently, the overlap welding structure of both types of steel is cut around the central spot weld, so as to obtain the cylindrical compression specimens of the RSW of QP980 steel and TRIP800 steel, respectively.

During the observation of the microstructure of the spot welding zone of the two grade steel, the spot welding zone is cut starting from the center. Subsequent to plastic packaging, grinding, and polishing, the metallographic specimens are prepared accordingly. Furthermore, the metallographic specimens are etched with the use of the $4 \%$ nitric acid alcohol solution as an etching agent before observation of their microstructure with a metallographic microscope.

To test the Vickers hardness of the spot welding zone of the two grade steel, the microhardness meter is adopted. During the experiment, the first step is to locate the points horizontally on the substrate. Next, subsequent to the entrance into the heat affected zone, we go through the nugget center along the diagonal line to reach the boundary of the heat-affected zone before going horizontally into the substrate. The spacing of adjacent points amounts to $0.2 \mathrm{~mm}$, whereas 44 points have been subject to the Vickers hardness experiment in total.

The quasi-static compression experiments are conducted on the cylindrical specimens of the RSW of QP980 steel and TRIP800 steel with a material testing machine. Furthermore, the dynamic compression experiments are carried out on the RSW of both grade steel with a split Hopkinson pressure bar, which is illustrated in Figure 2. The bullets, incident bars, transmission bars, and absorption bars used in the experiments are all made of the same grade high-strength steel with a diameter of $14.5 \mathrm{~mm}$ and a length of $30 \mathrm{~cm}, 100 \mathrm{~cm}, 100 \mathrm{~cm}$, and $60 \mathrm{~cm}$, respectively. The specimens are dynamically compressed at 25 degrees centigrade under heating conditions. The heating equipment is illustrated in Figure 3.

The original structure of RSW is cut (with the range of cutting as illustrated in Figure 4) to obtain the compression specimens of the RSW of the two grade steel. The diameter of 
TABLE 1: Welding parameters.

\begin{tabular}{lccc}
\hline & Welding force $(\mathrm{kN})$ & Welding electric current $(\mathrm{A})$ & Welding time $(\mathrm{ms})$ \\
\hline QP980 steel & 3.6 & 6000 & 170 \\
TRIP800 steel & 4.4 & 7500 & 135 \\
\hline
\end{tabular}

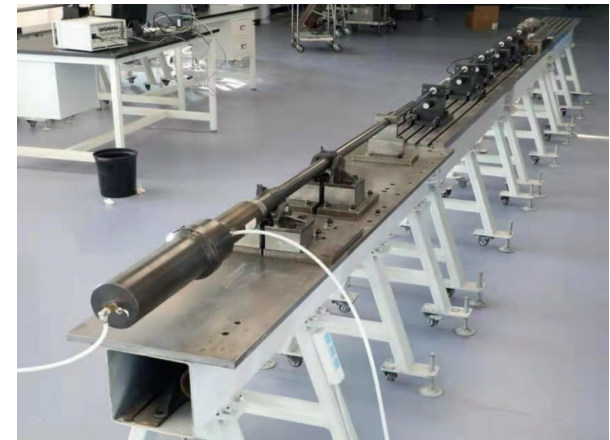

Figure 2: Split Hopkinson pressure bar.

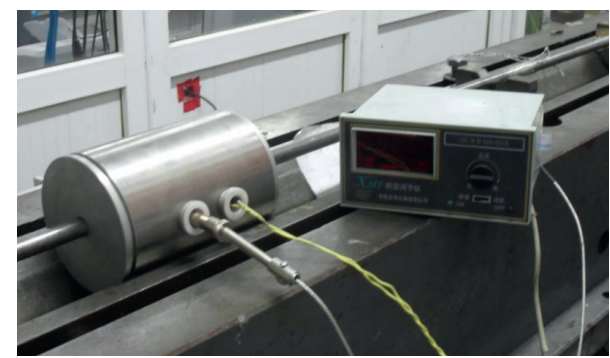

Figure 3: A heating device for the specimen in Hopkinson test.

the specimen of QP980 steel's spot welds amounts to $4.0 \mathrm{~mm}$, whereas the height amounts to about $2.3 \mathrm{~mm}$. The diameter of the specimen of TRIP800 steel's spot welds amounts to $4.0 \mathrm{~mm}$, whereas the height amounts to about $2.6 \mathrm{~mm}$

According to two basic assumptions of Hopkinson test [23], the bar is in one-dimensional stress state and the stress and strain are uniformly distributed along the length of the specimen. The stress $\sigma_{W}(t)$ and strain $\varepsilon_{W}(t)$ rate can be calculated in the spot welding specimen with the following equations:

$$
\begin{aligned}
& \sigma_{W}(t)=\frac{A_{B}}{A_{W}} E_{B} \varepsilon_{t}(t), \\
& \varepsilon_{W}(t)=-\frac{2 C_{B}}{L_{W}} \int_{0}^{t} \varepsilon_{r}(t) \mathrm{d} t, \\
& \dot{\varepsilon}_{W}(t)=-\frac{2 C_{B}}{L_{W}} \varepsilon_{r}(t),
\end{aligned}
$$

where $t$ is time, $\varepsilon_{t}(t)$ is the transmitted wave strain signal, $\varepsilon_{r}(t)$ is the reflected wave strain signal, $A_{B}$ is the crosssectional area of bar, $E_{B}$ is elastic modulus of bar, $C_{B}$ is elastic wave velocity of bar, $A_{W}$ is the cross-sectional area of specimen, and $L_{W}$ is length of the specimen.

\section{Results and Discussion}

The microstructure of the spot welding zone of the twograde steel is illustrated in Figure 5. The spot welding zone is divided into three zones, namely, melting zone, heat-affected zone, and substrate zone. The microstructure of the spot welding zone is primarily subjected to the control by temperature during welding. It can be evidently notified that transitional changes took place in the microstructure between the melting zone and the heat-affected zone as well as between the heat-affected zone and the substrate zone.

Given that, during the cooling procedure, the cooling rate is higher than the transformation rate of martensite, whereas the melting zone located in the center is subjected to the significant impact of the heat cycle. Consequently, the coarse lath martensite is generated, which features the coarse columnar grains (Figure 6). By contrast, the heat-affected zone is subjected to slighter impact of the heat cycle. As a result, the martensite is subjected to uniform transformation during cooling, leading to the generation of refine grains (Figure 7).

During the heat cycle of welding, crystallization took place in the inward direction, and the density of the martensite derived from crystallization exceeds the original density of the plate, leading to the formation of pores in between the coarse columnar crystals. In other words, porosity defects arise (Figure 8), and the closer to the center it is, the more severe the porosity would become. Welding cracks are observed on both the left and right sides of the spot welding zone of QP980 steel and TRIP800 steel (Figure 9). In addition, the microstructures of the substrate zone of QP980 steel's spot welds consist of martensite, ferrite, block M/A island, and retained austenite. The microstructures of the substrate zone of TRIP800 steel's spot welds consist of ferrite and block M/A island.

The Vickers hardness distribution of the spot welding zone of QP980 steel and TRIP800 steel is illustrated in Figure 10. It could be notified that the Vickers hardness of the spot welding zone of QP980 steel surpasses that of TRIP800 steel due to the higher level of carbon content (Table 2) of the former type of steel than that of the latter one, and this phenomenon consists of the relationship between the strength of the two grade steel. In addition, judging from the figure on the distribution of hardness in the spot welding zone of both grade steel, we may conclude that the average hardness of the melting zone ranks as the highest, followed by the heat-affected zone, and the substrate zone is the lowest. However, the hardness value of the heataffected zone is subject to the greatest range of changes. This is caused by the co-existence of two transitional zones in the heat-affected zone. One is the transitional zone between the melting zone and the heat-affected zone, where the martensite grain structure has experienced a transition from the coarse-grained lath structure into the uniform fine-grained 


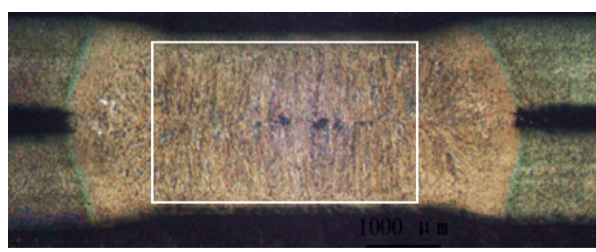

(a)

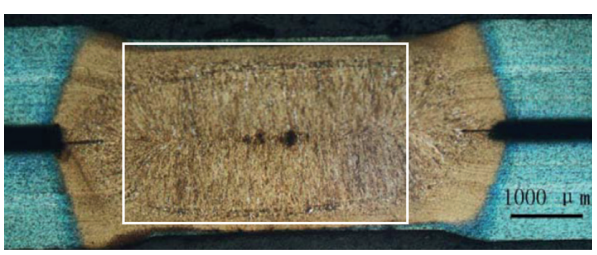

(b)

FIgURE 4: Cutting range. (a) QP980 steel RSW; (b) TRIP800 steel RSW.

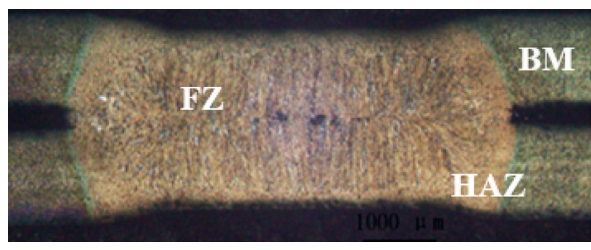

(a)

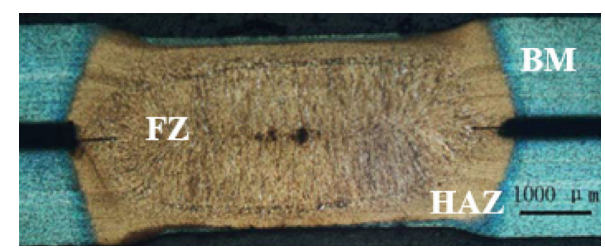

(b)

Figure 5: Microstructure of spot welding zone. (a) QP980 steel RSW; (b) TRIP800 steel RSW.

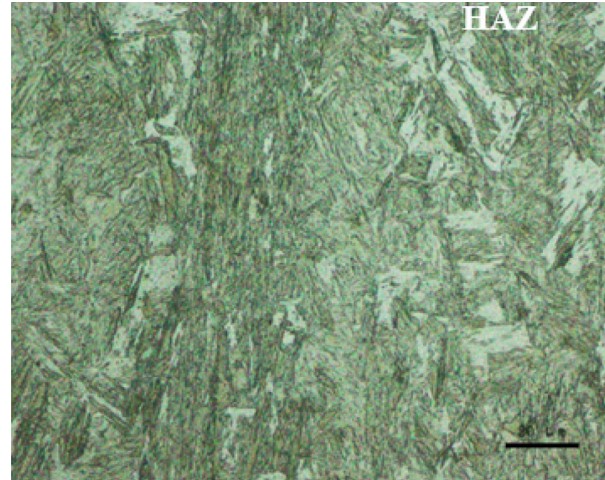

(a)

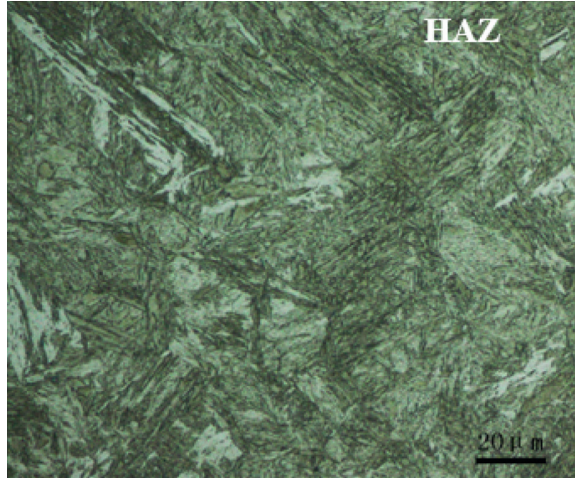

(b)

FIgURE 6: Coarse columnar grains. (a) QP980 steel RSW; (b) TRIP800 steel RSW.

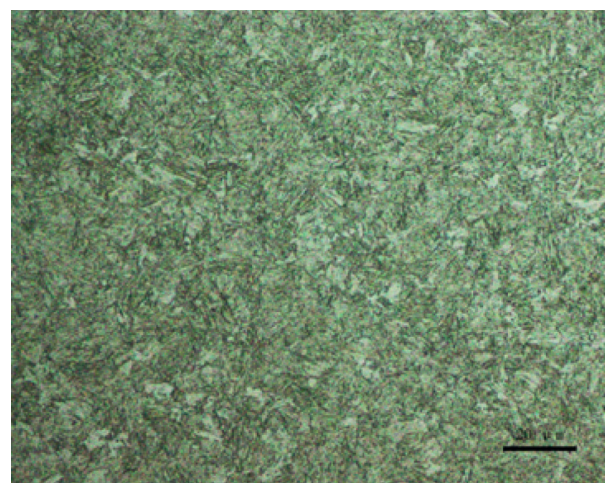

(a)

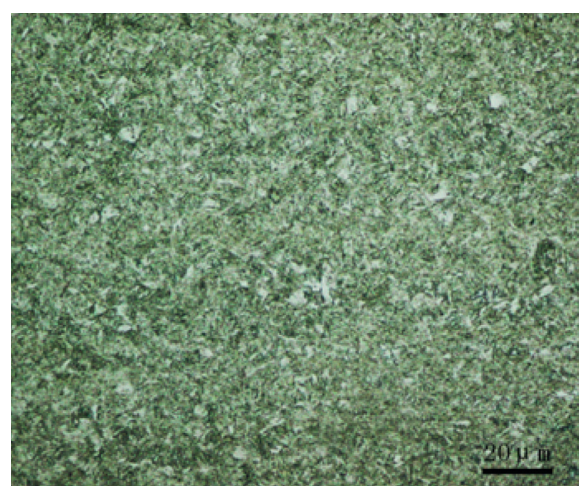

(b)

Figure 7: Refine grains. (a) QP980 steel RSW; (b) TRIP800 steel RSW.

structure. The other transitional zone is located between the heat-affected zone and the substrate zone, where the martensite grain structure has undergone a transition from the fine-grained structure into the substrate structure. In the heat-affected zone adjacent to the substrate zone, there is a region where the hardness value is lower than that of the base metal, which is referred to as the softening region (S). Such softening is caused by the tempering taken place in the martensite of this region, leading to its decomposition and the further decrease of hardness [24-27]. 


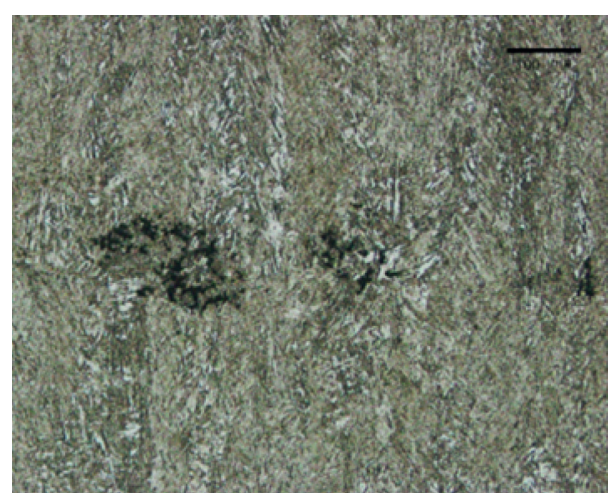

(a)

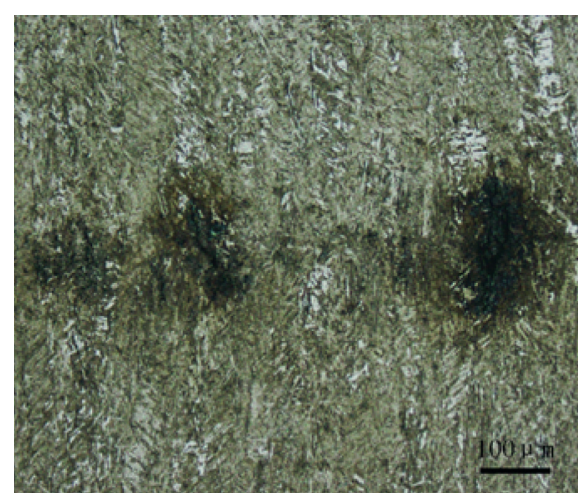

(b)

FIgURe 8: Loose defects. (a) QP980 steel RSW; (b) TRIP800 steel RSW.

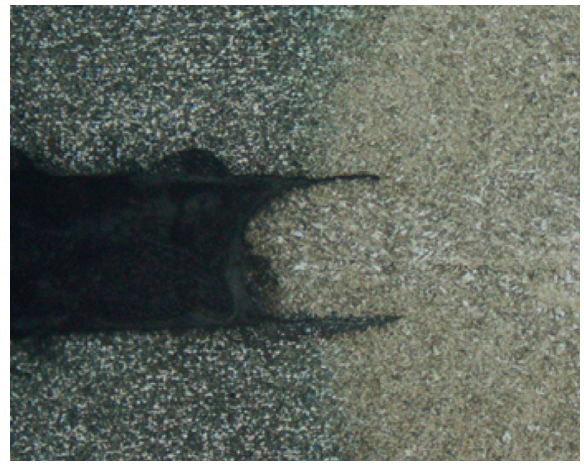

(a)

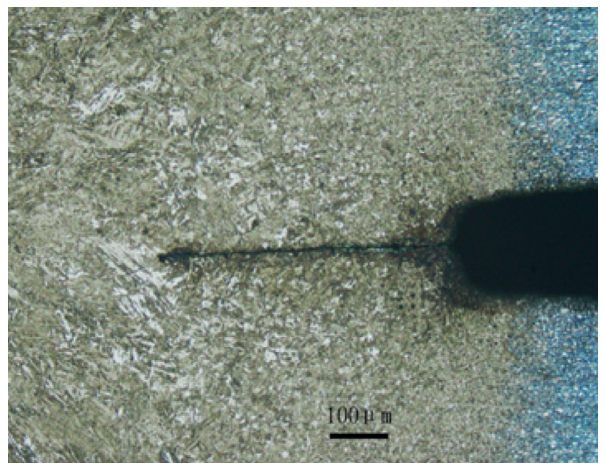

(b)

Figure 9: Weld line. (a) QP980 steel RSW; (b) TRIP800 steel RSW.

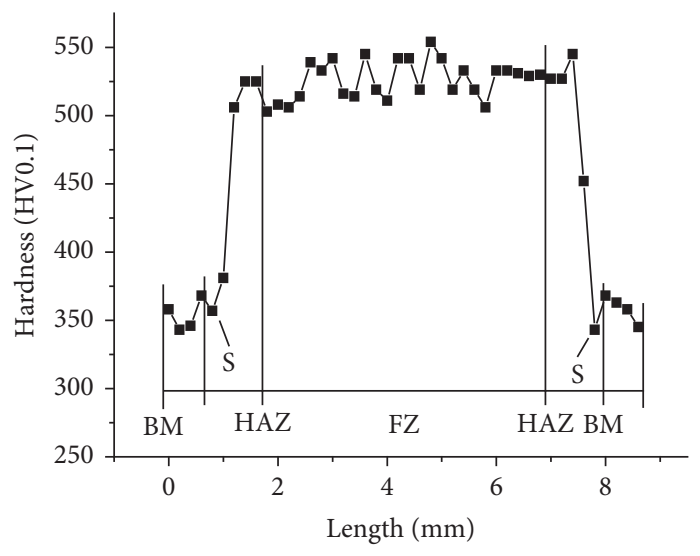

(a)

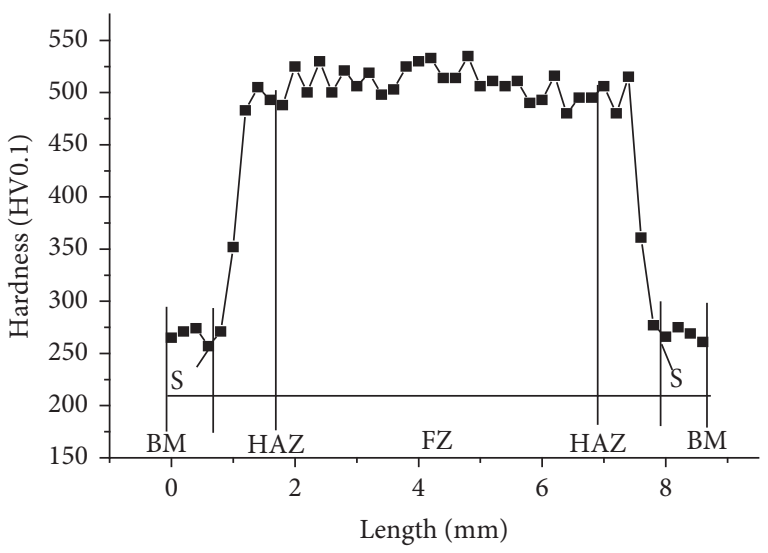

(b)

FIgURE 10: Microhardness profile. (a) QP980 steel RSW; (b) TRIP800 steel RSW.

TABLE 2: Chemical composition of two-grade steel.

\begin{tabular}{lcccccc}
\hline & $C$ & $\mathrm{Si}$ & $\mathrm{Mn}$ & $P$ & $S$ & $\mathrm{Al}$ \\
\hline QP980 steel & 0.22 & 1.49 & 1.82 & 0.017 & 0.0043 & 0.046 \\
TRIP800 steel & 0.20 & 0.73 & 1.69 & 0.050 & 0.0050 & 0.028 \\
\hline
\end{tabular}

The results of the quasi-static compression experiment on the cylindrical specimens of QP980 steel's spot welds and
TRIP800 steel's spot welds are illustrated in Figure 11. Judging from the two stress-strain curves, it can be found that the strength of QP980 steel's spot welds is evidently higher than that of TRIP800 steel's spot welds.

The conditions for the dynamic compression experiment on the cylindrical specimens of the spot welds of QP980 steel and TRIP800 steel at room temperature are specified in Tables 3 and 4. In addition, the dynamic compressive stress- 


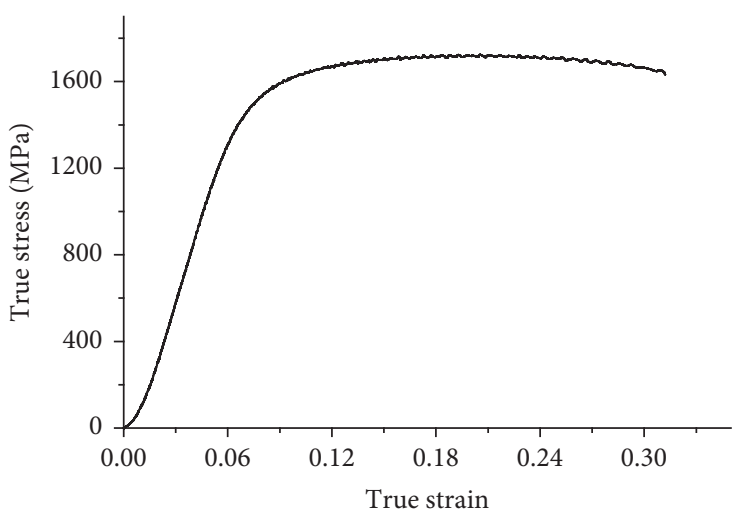

(a)

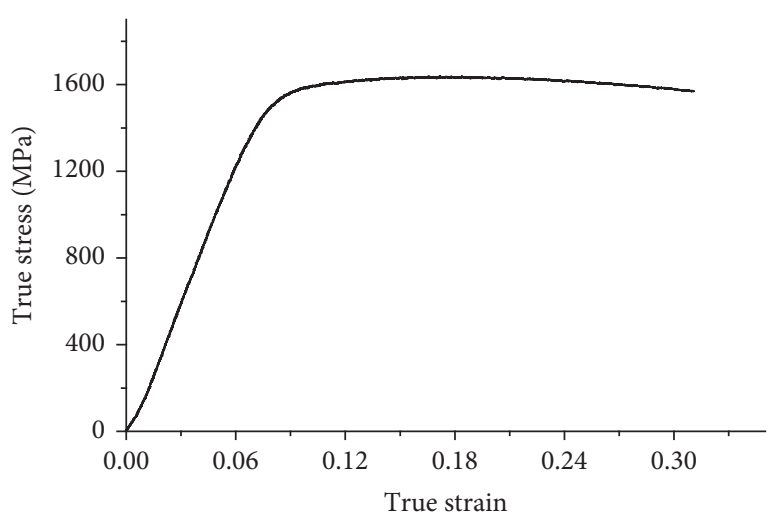

(b)

FIGURE 11: Quasi-static compressive stress-strain curve. (a) QP980 steel RSW; (b) TRIP800 steel RSW.

TABLE 3: Experimental conditions of the dynamic compression of QP980 steel spot welds at room temperature.

\begin{tabular}{lccc}
\hline & Temperature $\left({ }^{\circ} \mathrm{C}\right)$ & Height of specimen $(\mathrm{mm})$ & Diameter of specimen $(\mathrm{mm})$ \\
\hline Test 1 & 25 & 2.28 & 4.03 \\
Test 2 & 25 & 2.27 & 4.03 \\
Test 3 & 25 & 2.30 & 4.01 \\
Test 4 & 25 & 2.28 & 4.03 \\
\hline
\end{tabular}

TABLE 4: Experimental conditions of the dynamic compression of TRIP800 steel spot welds at room temperature.

\begin{tabular}{lccc}
\hline & Temperature $\left({ }^{\circ} \mathrm{C}\right)$ & Height of specimen $(\mathrm{mm})$ & Diameter of specimen $(\mathrm{mm})$ \\
\hline Test 5 & 25 & 2.58 & 4.02 \\
Test 6 & 25 & 2.59 & 4.01 \\
Test 7 & 25 & 2.61 & 4.01 \\
Test 8 & 25 & 2.58 & 4.03 \\
\hline
\end{tabular}

strain curves of the spot welds of QP980 steel and TRIP800 steel at room temperature are illustrated in Figure 12. Judging from Figure 12, it can be found that, as the strain rate climbs up, the compressive stress in the RSW of the twograde steel would experience increases accordingly, but such increases would remain at a small range. Our research findings indicate that the material of the spot welding zone could impose an effect on the strain rate to a certain extent, though it is not quite evident. The recovered specimens for the dynamic compression experiments on the spot welds of QP980 steel and TRIP800 steel at room temperature have been flattened, and there has been huge plastic deformation without any fracture taken place.

The conditions for the dynamic compression experiment on the cylindrical specimens of the spot welds of QP980 steel and TRIP800 steel under heating conditions are specified in Tables 5 and 6 . The dynamic compressive stress-strain curves of the RSW of both grade steel under heating conditions are illustrated in Figure 13. Judging from Figure 13, we may conclude that, under heating conditions, the strain rate is high, whereas the stress peak value is rather low. The research findings indicate that, with the rising temperature, the strain would rise accordingly, but the strength would decrease correspondingly. Moreover, it should be noted that, with higher strain rate, the stress would enter into a stage of decreasing before experiencing a rebound. From our perspective, this is because porosity and crystal defects exist at the nugget center, and when compressed smaller under heating conditions, such porosity would result in a diminished compressive strength of nugget and stress. By contrast, with the disappearance of the pores, the compressive strength of nugget would increase, leading to a larger stress. The recovered specimens for the dynamic compression experiments on the spot welds of QP980 steel and TRIP800 steel under heating conditions are illustrated in Figure 14. Judging from Figure 14, the specimens have been flattened and even broken, whereas the fracture surface has expanded from the nugget center to the circumference.

At present, the majority of the existing studies focus on the base material of the steel. However, few empirical studies have been conducted on the dynamic compression of cylindrical specimens of spot welding materials. In addition, the dynamic compression under heating condition is less discussed, so it is the fracture mode of spot welding materials under dynamic compression. In this study, we have observed the fracture surface of the recovered specimens of the spot welds of QP980 steel and TRIP800 steel using a scanning electron microscope. It is found that the fracture mode of the sample is more complicated, whereas the fracture surface features a number of "river pattern" cleavage facets. Moreover, there are very few dimples of ductile tearing [28-30], whereas the fracture of nugget is brittle (Figure 15), 


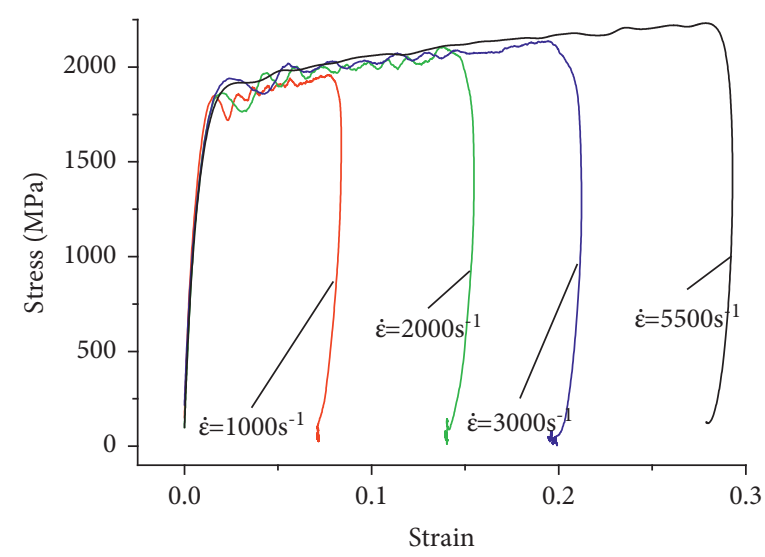

(a)

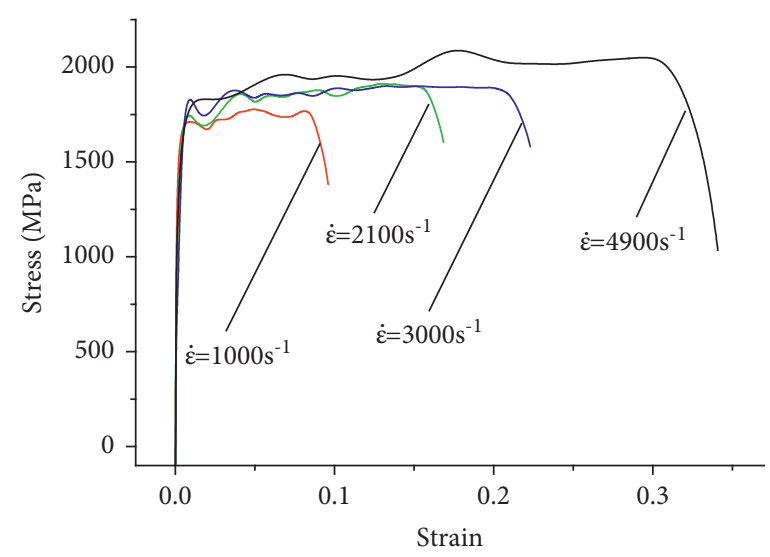

(b)

Figure 12: Dynamic compression stress-strain curve at room temperature. (a) QP980 steel RSW; (b) TRIP800 steel RSW.

TABLE 5: Experimental conditions of the dynamic compression of QP980 steel spot welds under heating condition.

\begin{tabular}{lccr}
\hline & Temperature $\left({ }^{\circ} \mathrm{C}\right)$ & Height of specimen $(\mathrm{mm})$ & Diameter of specimen $(\mathrm{mm})$ \\
\hline Test 9 & 200 & 2.29 & 4.02 \\
Test 10 & 300 & 2.30 & 4.01 \\
\hline
\end{tabular}

TABLE 6: Experimental conditions of the dynamic compression of TRIP800 spot welds under heating condition.

\begin{tabular}{lccc}
\hline & Temperature $\left({ }^{\circ} \mathrm{C}\right)$ & Height of specimen $(\mathrm{mm})$ & Diameter of specimen $(\mathrm{mm})$ \\
\hline Test 11 & 200 & 2.57 & 4.03 \\
Test 12 & 300 & 2.58 & 4.01 \\
\hline
\end{tabular}

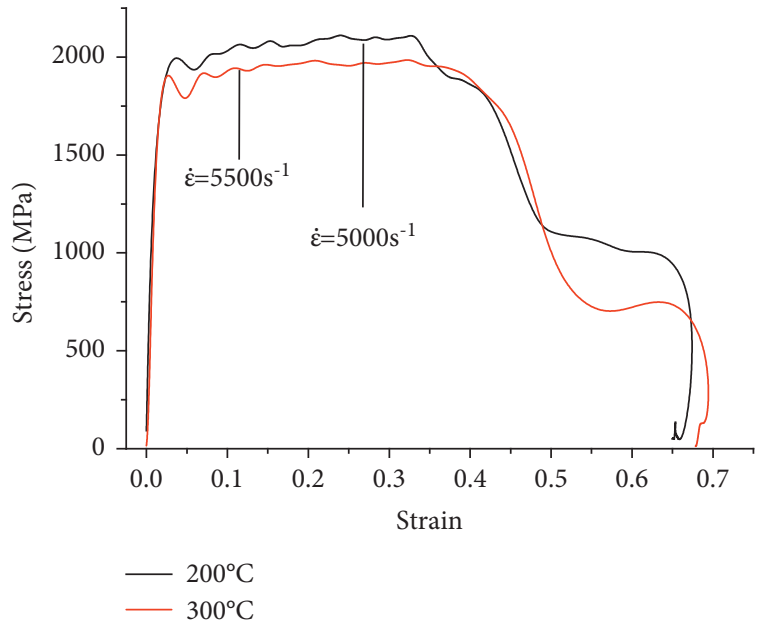

(a)

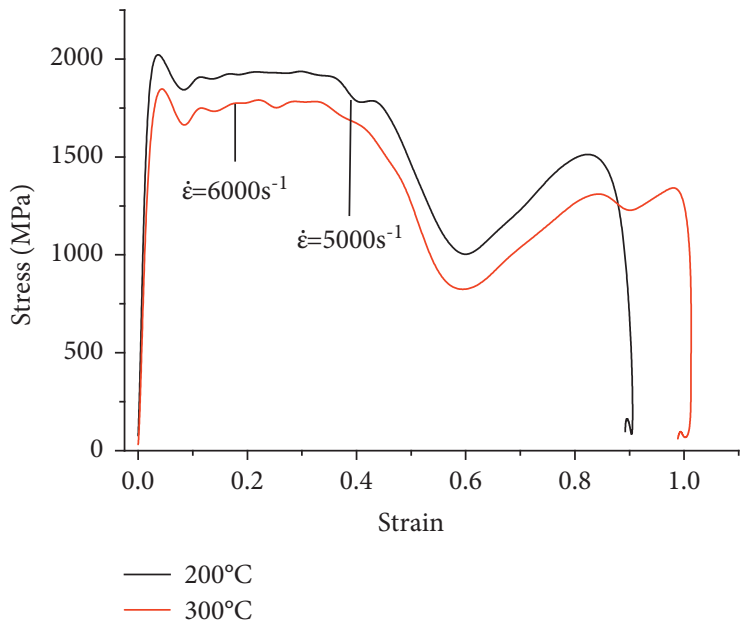

(b)

FIGURE 13: Dynamic compression stress-strain curve at varying temperature. (a) QP980 steel RSW; (b) TRIP800 steel RSW.

indicating its fragility in nature. At the microscopic scale, it is found that the damage evolution of original microcracks exists on the fracture surface of the recovered specimens [31]. Subsequent to the nucleation, expansion, and connection of the original microcracks with the porosity defects at the nugget center, a continuous surface would be formed, leading to the formation of the brittle fracture in the recovered specimens. 


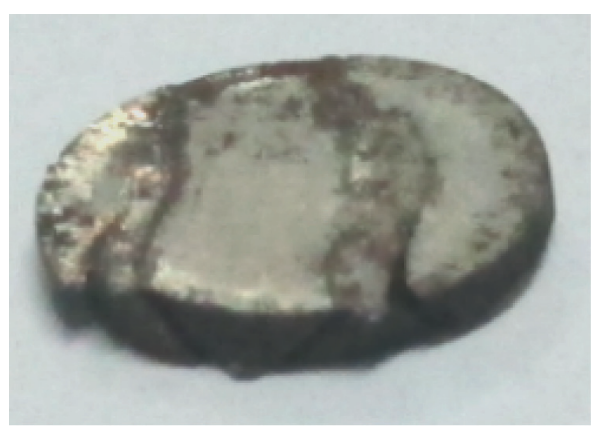

(a)

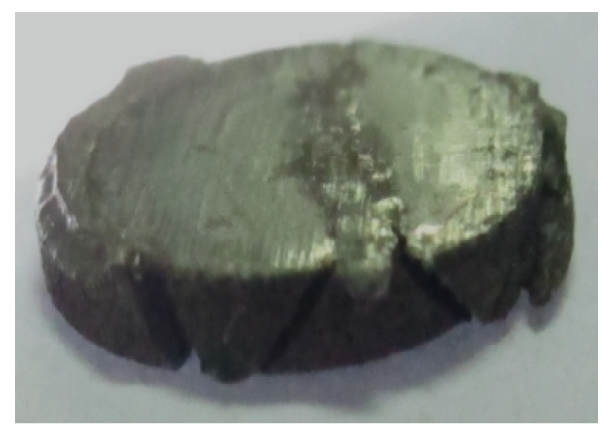

(b)

FIGURE 14: Recycled specimens for dynamic compression experiments at varying temperature. (a) QP980 steel RSW; (b) TRIP800 steel RSW.

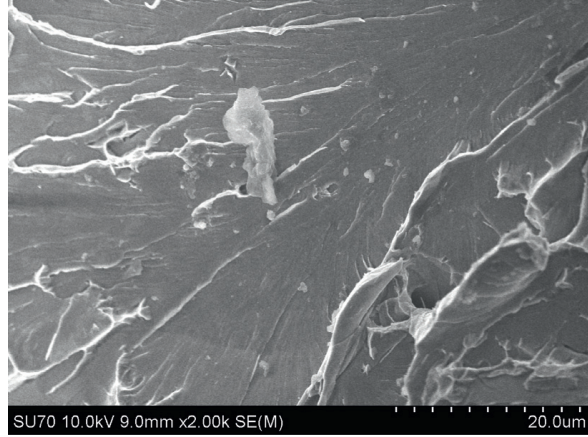

(a)

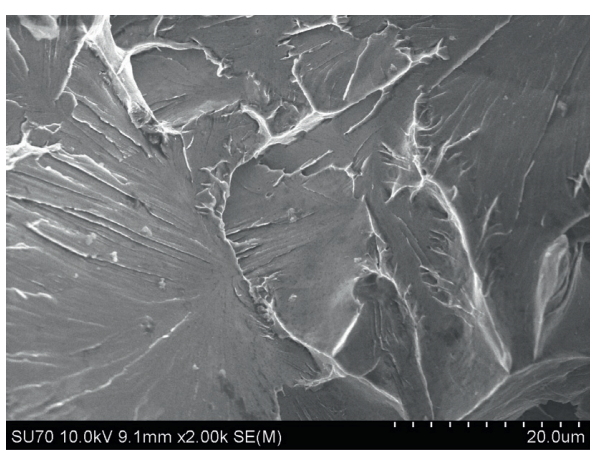

(b)

FIgURE 15: SEM results. (a) QP980 steel RSW; (b) TRIP800 steel RSW.

\section{Conclusions}

In this paper, we have studied the dynamic compression performance of the RSW of QP980 steel and TRIP800 steel, and we have also examined the fracture mode of the two research objects. Judging from our research, we may draw the following conclusions:

(1) Through the observation of the microstructure of the RSW of the two-grade steel, it is found that the nugget center is located in the crystal structure of the coarse martensite featuring porosity defects. In addition, there are evident gaps between the plates on both sides of the spot welding zone.

(2) Through the experiments on the microhardness of the two-grade steel, it is found that the average hardness of the RSW of QP980 steel surpasses that of TRIP800 steel. There is a softening region in the interface of the heat-affected zone and the substrate zone.

(3) The dynamic compression experiments are carried out on the RSW of QP980 steel and TRIP800 steel under heating conditions $\left(20^{\circ} \mathrm{C}\right.$ and $\left.300^{\circ} \mathrm{C}\right)$. It is found that the strain rate would increase with the rising temperature, but the compressive strength would experience declines. Furthermore, the porosity defects of the crystal structure at the weld nugget center would lead to stress rebound when the specimen is compressed.

(4) Through the observation of the fracture surface of the recovered specimens, it is found that the fracture of the nugget is brittle. Moreover, the fracture mode of the sample is more complicated, whereas the fracture surface features a number of "river pattern" cleavage facets, and there are very few dimples of ductile tearing.

\section{Data Availability}

The data used to support the findings of this study are included within the article.

\section{Conflicts of Interest}

The authors declare that there are no conflicts of interest regarding the publication of this paper.

\section{References}

[1] L. Wang and J. G. Speer, "Quenching and partitioning steel heat treatment," Metallography, Microstructure, and Analysis, vol. 2, no. 4, pp. 268-281, 2013.

[2] J. Speer, D. K. Matlock, B. C. De Cooman, and J. G. Schroth, "Carbon partitioning into austenite after martensite 
transformation," Acta Materialia, vol. 51, no. 9, pp. 2611-2622, 2003.

[3] V. F. Zackay, E. R. Parker, and D. Fahr, "The enhancement of ductility on high-strength steel," Transactions of Applied Structures Mechanics, vol. 60, pp. 252-258, 1967.

[4] A. Srivastava, H. Ghassemi-Armaki, H. Sung, P. Chen, S. Kumar, and A. F. Bower, "Micromechanics of plastic deformation and phase transformation in a three-phase TRIPassisted advanced high strength steel: experiments and modeling," Journal of the Mechanics and Physics of Solids, vol. 78, pp. 46-69, 2015.

[5] X. Yang, L. G. Hector, and J. Wang, "A combined theoretical/ experimental approach for reducing ringing artifacts in low dynamic testing with servo-hydraulic load frames," Experimental Mechanics, vol. 54, no. 5, pp. 775-789, 2014.

[6] X. H. Hu, X. Sun, L. G. Hector, and Y. Ren, "Individual phase constitutive properties of a TRIP-assisted QP980 steel from a combined synchrotron X-ray diffraction and crystal plasticity approach," Acta Materialia, vol. 132, pp. 230-244, 2017.

[7] H. Wang, W. Zhang, D. Ma et al., "Dynamic response of a Q\&P steel to high-strain-rate tension," Acta Mechanica Solida Sinica, vol. 30, no. 5, pp. 484-492, 2017.

[8] P. J. Jacques, Q. Furnémont, F. Lani, T. Pardoen, and F. Delannay, "Multiscale mechanics of TRIP-assisted multiphase steels: I. characterization and mechanical testing," Acta Materialia, vol. 55, no. 11, pp. 3681-3693, 2007.

[9] A. K. Srivastava, G. Jha, N. Gope, and S. B. Singh, "Effect of heat treatment on microstructure and mechanical properties of cold rolled C-Mn-Si TRIP-aided steel," Materials Characterization, vol. 57, no. 2, pp. 127-135, 2006.

[10] M. Dunand and D. Mohr, "Ductile fracture of TRIP780 sheets under multi-axial loading," AIP Conference Proceedings, vol. 1252, no. 1, p. 1295, 2010.

[11] H. Y.. Yu and C. C. Ai, "Work hardening response of transformation-induced plasticity and dual-phase steels to prestrain," Steel Research International, vol. 84, no. 10, pp. 1040-1045, 2013.

[12] R. Kussa, I. Kushchenko, V. Andilakhai, I. Petryshynets, V. Efremenko, and V. Zurnadzhy, "Austenite transformation behavior and mechanical properties of constructional v, nballoyed trip-assisted steel," Key Engineering Materials, vol. 864, pp. 241-249, 2020.

[13] B. Fu, W. Y. Yang, L. F. Li, and Z. Y. Zhao, "Effect of transformation behavior of retained austenite on mechanical properties of cold-rolled trip steel," Cailiao Rechuli Xuebao/ Transactions of Materials and Heat Treatment, vol. 38, no. 12, pp. 63-69, 2017.

[14] Y. J. Chao, K. Wang, K. W. Miller, and X.-K. Zhu, "Dynamic separation of resistance spot welded joints: Part I-experiments," Experimental Mechanics, vol. 50, no. 7, pp. 889-900, 2010.

[15] B. Langrand and E. Markiewicz, "Strain-rate dependence in spot welds: non-linear behaviour and failure in pure and combined modes I/II," International Journal of Impact Engineering, vol. 37, no. 7, pp. 792-805, 2010.

[16] S. Dancette, D. Fabrègue, V. Massardier, J. Merlin, T. Dupuy, and M. Bouzekri, "Experimental and modeling investigation of the failure resistance of advanced high strength steels spot welds," Engineering Fracture Mechanics, vol. 78, no. 10, pp. 2259-2272, 2011.

[17] W. Noh, W. Kim, X. Yang, M. Kang, M.-G. Lee, and K. Chung, "Simple and effective failure analysis of dissimilar resistance spot welded advanced high strength steel sheets,"
International Journal of Mechanical Sciences, vol. 121, pp. 76-89, 2017.

[18] I. A. Soomro, S. R. Pedapati, and M. Awang, "Double pulse resistance spot welding of dual phase steel: parametric study on microstructure, failure mode and low dynamic tensile shear properties," Materials, vol. 14, no. 4, p. 802, 2021.

[19] C. T. Sezgin and F. Hayat, "The microstructure and mechanical behavior of trip 800 and dp 1000 steels welded by electron beam welding method," Soldagem \& Inspeção, vol. 25 , no. 1 , pp. $1-12,2020$.

[20] H. E. Emre and R. Kacar, "Development of weld lobe for resistance spot-welded trip800 steel and evaluation of fracture mode of its weldment," International Journal of Advanced Manufacturing Technology, vol. 83, no. 9-12, pp. 1737-1747, 2016.

[21] H. Wu, B. Zhao, H. Gao, Z. B. Zhao, and C. Liu, "Microstructure and fatigue fracture of spot welded trip800 steel," Applied Mechanics and Materials, vol. 789-790, pp. 15-19, 2015.

[22] U. Zsara, V. Onar, F. Zen, Y. S. Aslanlar, and S. Aslanlar, "Effect of welding time on tensile-shear load in resistance spot welded trip 800 and microalloyed steels," Indian Journal of Chemical Technology, vol. 26, pp. 355-357, 2019.

[23] ANSI/AWS/SAE/D8.9-97, Recommended Practices for Test Methods for Evaluating the Resistance Spot Welding Behavior of Automotive Sheet Steel Materials, American Welding Society, Miami, FL, USA, 1997.

[24] M. Xia, E. Biro, Z. Tian, and Y. N. Zhou, "Effects of heat input and martensite on HAZ softening in laser welding of dual phase steels," ISIJ International, vol. 48, no. 6, pp. 809-814, 2008.

[25] M. Marya, K. Wang, L. G. Hector, and X. Gayden, "Tensileshear forces and fracture modes in single and multiple weld specimens in dual-phase steels," Journal of Manufacturing Science and Engineering, vol. 128, no. 1, pp. 287-298, 2006.

[26] S. K. Panda, N. Sreenivassan, M. L. Kuntz, and Y. Zhou, "Numerical simulations and experimental results of tensile test behavior of laser butt welded DP980 steels," Journal of Engineering Materials and Technology, vol. 130, no. 4, pp. 531-534, 2008.

[27] V. H. Baltazar Hernandez, S. K. Panda, M. L. Kuntz, and Y. Zhou, "Nanoindentation and microstructure analysis of resistance spot welded dual phase steel," Materials Letters, vol. 64, no. 2, pp. 207-210, 2010.

[28] S. Nitin, P. Chandan, M. M. Manas, H. K. Narang, R. S. Mulik, and K. Pradeep, "A comparative study of ductile-brittle transition behavior and fractography of p91 and p92 steel," Engineering Failure Analysis, vol. 81, pp. 245-253, 2017.

[29] C. Pandey, M. M. Mahapatra, P. Kumar et al., "Study on effect of double austenitization treatment on fracture morphology tensile tested nuclear grade p92 steel," Engineering Failure Analysis, vol. 96, no. 1, pp. 158-167, 2019.

[30] C. PandeY, N. Saini, M. M. Mahapatra, and P. Kumar, "Study of the fracture surface morphology of impact and tensile tested cast and forged (C\&F) Grade 91 steel at room temperature for different heat treatment regimes," Engineering Failure Analysis, vol. 71, pp. 131-147, 2017.

[31] S. Wu, D. Chen, D. Ma, H. Wang, and Y.. Hou, "Dynamic growth and coalescence of drilled voids in pure copper sheets," International Journal of Nonlinear Sciences and Numerical Stimulation, vol. 13, no. 3, pp. 225-231, 2012. 